\title{
Deposition and characterization of ITO thin film over glass for defogger application and for solar photovoltaics
}

\author{
M. S. Siddiqui*, A.K.Saxena and S. P. Singh \\ †BHEL, Amorphous Silicon Solar Cell Plant, Gurgaon, Haryana-122002, India \\ Received 01 May 2018, Accepted 01 July 2018, Available online 02 July 2018, Vol.8, No.4 (July/Aug 2018)
}

\begin{abstract}
Indium thin oxide (ITO) films have been used in solar cell applications as top conducting layers for many years. These films possess very good transmission and a low sheet resistance thus making them ideal candidate material for top conducting layers in thin film and HIT solar cells. In the present work, ITO films have been deposited over soda lime glass substrates for use as defogger applications, and for use as front contact electrode in HIT type solar cells as well. ITO deposition is done using pulsed DC sputtering technique inside a vacuum chamber with large size ITO sputtering target of 15 inches by 5 inches. Silver bus bars are printed at the two edges of glass using thick film screen printing technique and the firing of thick film is done in a belt furnace. The deposited ITO thin film characterization is done by using XRD, SEM and 4 probe sheet resistance measurement techniques. The transmission spectra is analyzed for optical transmission properties.
\end{abstract}

Keywords: Indium Tin Oxide (ITO), Defogger, sheet resistance, transmission, transparent electrode.

\section{Introduction}

ITO is a very important transparent conducting oxide (TCO) and has applications in variety of fields such as flat panel displays, light emitting diodes, solar cells and optical coatings [L. Kerkache et al, 2010; Minami et al, 2005; Venkat et al, 2006; T. K. Kim et al, 2009]. In the present work, an effort is made to develop ITO coatings having low sheet resistance and high transmission for use as defogger application and as front contact electrode for HIT type of solar cell. ITO coating is deposited using pulsed DC sputtering technique and their suitability for application as defogger is examined. The applications of ITO coatings as defogger and for solar photovoltaics have been investigated by several researchers in the recent past [Subrata Roy et al, 2005; A. Farag et al, 2003; R. W. Gent et al, 2000; SAE International 2003]. ITO thin films can be deposited by various techniques such as thermal evaporation, DC sputtering, RF sputtering, pulsed laser deposition etc [M. Nisha et al, 2008; L. Kerkache et al, 2009; T. F. Stoica et al, 2003; J. B. Choi et al, 2003]. Traditionally air jet impingement method has been used successfully for several decades for defogging for automotive and aircraft industry. However Subrata Roy et al have simulated and compared the air jet impingement design and joule heating defroster using ITO as transparent electrodes and found that $70 \%$ reduction in defrosting time in observed for joule heating defroster [Subrata Roy et al, 2005].

\section{Experimental}

A picture of the sputtering chamber in which ITO coatings are deposited is shown in figure 1 . The approximate dimensions of sputtering chambers are 5 $\mathrm{ft}$ by $2 \mathrm{ft}$ by 10 inches. This is an integrated line capable of depositing $\mathrm{p}$, $\mathrm{i}$ or $\mathrm{n}$ layers of amorphous silicon for thin film amorphous silicon solar cell also, along with ITO layers over glass substrates as large as $3 \mathrm{ft}$ by $1 \mathrm{ft}$. The glass substrates are heated inside the vacuum chamber to approximately 200 degrees Celsius and soaked for 1 hour prior to sputtering.

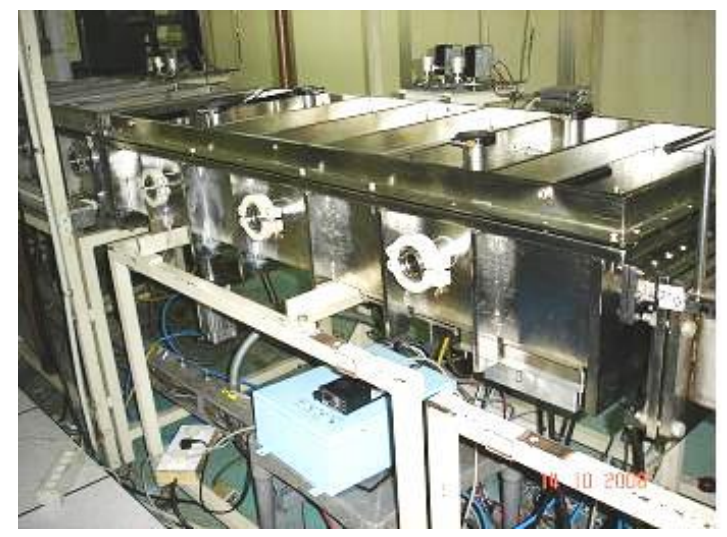

Fig. 1 ITO sputter deposition chamber 
A base pressure of $1 \times 10^{-6}$ torr is reached in the sputtering chamber before introducing the sputtering gases. Large size ITO sputtering target (composition: $90 \mathrm{wt} \% \mathrm{In}_{2} \mathrm{O}_{3}$ and $10 \mathrm{wt} \% \mathrm{SnO}_{2}$ ) of size 15 inches by 5 inches are used for sputtering. A mixture of pure Argon and $3 \%$ oxygen in $\mathrm{Ar}$ gases are used for sputter deposition of ITO. SIERRA Instruments Inc. manufactured mass flow controllers are used to control the flow of gases. The sputtering pressure is varied between 4 milli-Torr to 8 milli-Torr. Soda lime glass substrates are cut to approximate size of $130 \mathrm{~mm}$ by $58 \mathrm{~mm}$. The thickness of glass is $4 \mathrm{~mm}$. Glass pieces are cleaned properly using scrubber and detergent to remove any oil or fluid used during cutting process. The glass pieces are subsequently cleaned with IP solution and rinsed with DI water before drying. A mks make model RPG-50 DC power supply is used as the power source and sputtering power is kept in between $300 \mathrm{~W}$ to $500 \mathrm{~W}$. Sputtering is done on a moving substrate and the speed of substrate is controlled to achieve the required coating thickness. Before ITO deposition, thick film screen printing technique was used for printing of silver bus bars ( $4 \mathrm{~mm}$ wide) at the edges of the glass substrate as shown in figure 2. Ferro NS 311 silver conductor paste is used for thick film screen printing. The screen printed samples are dried at $150^{\circ}$ Celsius and fired at $550^{\circ}$ Celsius in the belt furnace. The speed of belt is kept at approximately 6 inches per minute. A picture of ITO coated and silver conductor screen printed sample is shown in figure 2.

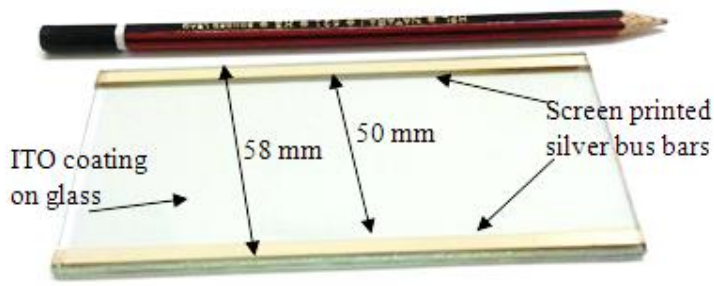

Fig. 2 ITO coated sample and screen printed silver bus bars over glass.

\section{Results and Discussion}

\subsection{Coating thickness}

Thickness of the ITO layer on glass substrate is determined by Alpha Step, Tencor Instruments, USA. The coating thickness required to achieve the desired properties of transmission and sheet resistance is approximately $700 \mathrm{~A}^{\circ}$. However for characterization purpose samples with 0.25 micron thickness were also prepared and measured.

\subsection{Ray Diffraction (XRD)}

XRD of ITO coatings is done at National physical laboratory (NPL), Delhi and at IIT Bombay. XRD analysis done at NPL Delhi of ITO coating samples were of approximately $700 \mathrm{~A}^{\circ}$ thickness and grazing angle XRD technique is used as the film thickness is less. Figure 3(a) shows the XRD pattern showing the (222) peak corresponding to $100 \%$ intensity at approximately 30 degrees. This experimental results suggest that the deposited ITO coatings of approximately $700 \mathrm{~A}^{\circ}$ thickness are crystalline in nature with (222) preferred orientation.

For samples having ITO coating thickness approximately 0.25 micron exhibited (400) as preferred orientation. The peaks obtained for thicker ITO coated sample were stronger suggesting a better degree of crystallinity for thick samples. XRD experiment on thick coating sample was done at IIT Bombay.

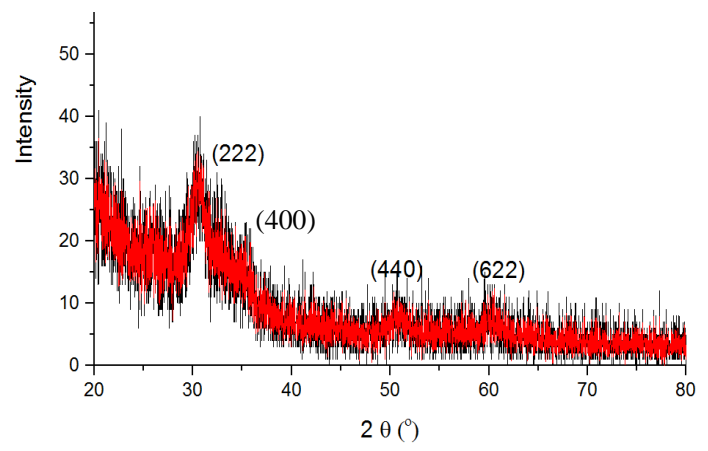

Fig. 3 (a) XRD pattern of ITO coating $\left(700 \mathrm{~A}^{\circ}\right.$ thickness) on glass

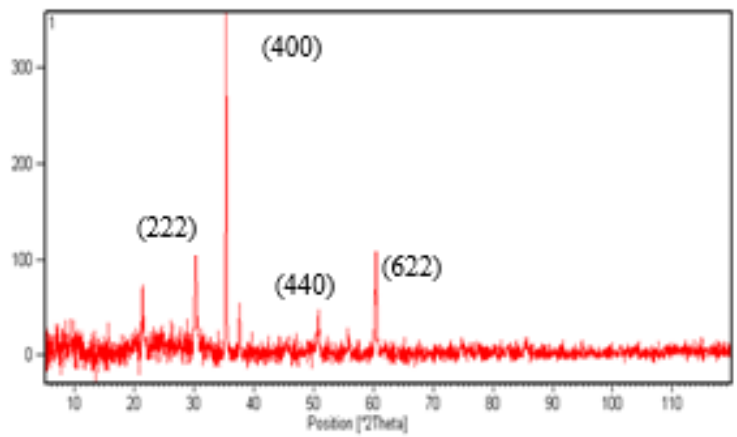

Fig. 3 (b) XRD pattern of ITO coating $(0.25 \mu \mathrm{m}$ thickness) on glass

Change in preferred orientation was observed by previous researchers such as Chen Y et al where they observed that the change from (222) preferred orientation to (400) orientation occurred by reduction in oxygen partial pressure during the growth process [Chen Y. et al, 2007]. Similarly Ocal Tuna et al reported that they found the change in crystal orientation from (222) plane to (400) plane when they increased the deposition temperature from $150^{\circ} \mathrm{C}$ to $300^{\circ} \mathrm{C}$ [Ocal Tune et al, 2010]. Change in orientation with the change in thickness was also observed by L. Kerkache et al when they found that thinner films have $<100>$ texture and it changes to $<111>$ as the film thickness increases [L. Kerkache et al, 2010]. The change in their thickness was from $171 \mathrm{~nm}$ to $513 \mathrm{~nm}$. 


\subsection{Scanning Electron Microscopy (SEM)}

Scanning electron microscopy (SEM) analysis was done at IIT Bombay using FESEM model Jeol JSM-7600F instrument. Figure 5 (a) and 5(b) below are two images at 30000X and 40000X magnifications showing the ITO coating morphology. The coating appears to be dense granular with average grain size varying in between 50 to $100 \mathrm{~nm}$. Similar SEM images of ITO thin film deposited by sputtering and e-beam evaporation were also taken by previous researchers and were found to have dense granular structure [L. Kerkache et al, 2010; Shui-Yang Lien, 2010].
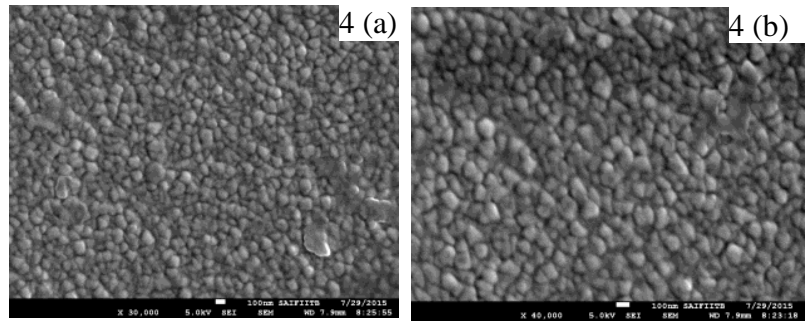

Fig. $4(\mathbf{a}, \mathbf{b})$ SEM images at 30,000 $\mathrm{X}$ and 40,000 X

3.4 Sheet resistance and resistance across the silver bus bars

Sheet resistance is measured using 4 probe technique. A SES instrument ltd. make four probe setup is used. Sheet resistance is found to be in the range of $30 \Omega / \square$ to $55 \Omega / \square$ depending on the thickness of the coated samples and on the ratio of the partial pressure of oxygen gas in Argon-oxygen mixture in the sputtering gas. Samples having transmission more than $80 \%$ with ITO coating thickness of approximately $700 \mathrm{~A}^{\circ}$ shows sheet resistance in the range of $40 \Omega / \square$ to $50 \Omega / \square$. Resistance across the bars are measured for different samples and are in the range of $15 \Omega$ to $25 \Omega$. Sheet resistance values obtained by Shui-Yang Lien in her work were varying in between 25 to $45 \Omega / \square$ with the variation in the substrate deposition temperature, however they used e-beam evaporation technique for ITO deposition [Shui-Yang Lien, 2010].

\subsection{Transmittance}

Transmission of ITO coated samples over glass is measured using Perkin Elmer model Lambda 35 UV-Vis Spectrophotometer. High transparency of ITO thin films is considered as one of the most critical factor in evaluating their performance for use in the photovoltaic devices and for application as defogger [Shui-Yang Lien, 2010]. The average transmission for the wavelength $500 \mathrm{~nm}$ to $750 \mathrm{~nm}$ is more than $80 \%$ which makes it suitable for use as defogger application. Figure 5 below shows a screen shot of the transmission spectra for a $700 \mathrm{~A}^{\circ}$ ITO coating thickness on glass.

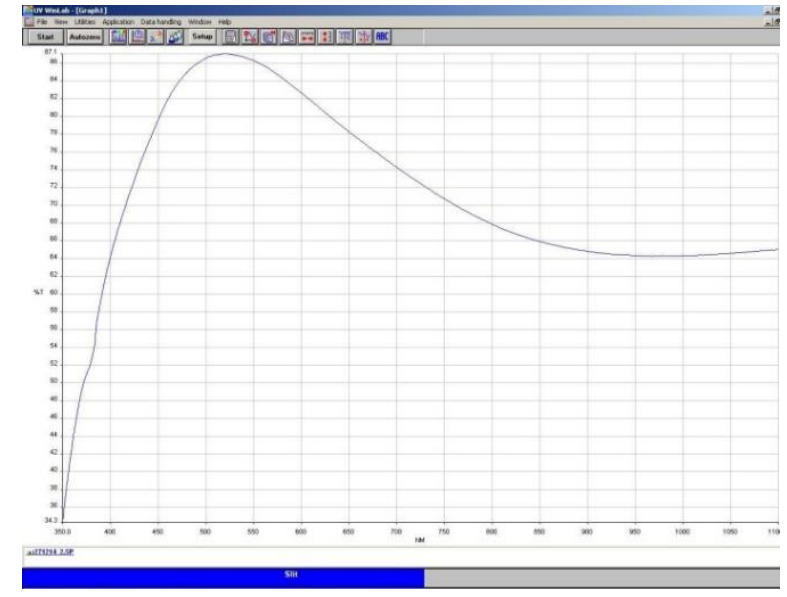

Fig. 5 Transmission spectra of ITO coated samples over glass for $700 \mathrm{~A}^{\circ}$ thick coating

\subsection{Defogging experiment}

The ITO coated glass sample with screen printed silver bus bars and a plane glass piece with no coating on it are kept inside the freezer compartment of a refrigerator for approximately 10 minutes before the experiment and are taken out just before the start of experiment. A thin layer of fog forms at both samples. The surface which does not have ITO coating is cleaned with a lint free tissue paper and then the sample is connected with a DC power supply as shown in figure 6 $(a, b, c, d)$ below. It can be see that initially the text underneath both the glass pieces could not be seen through the glass pieces because of the fog as shown in figure 6 (a). The power was already set so that on making the electrical connections at approximately 25 $\mathrm{V}$ the current is approximately 1.05 Ampere (power $26 \mathrm{~W})$.
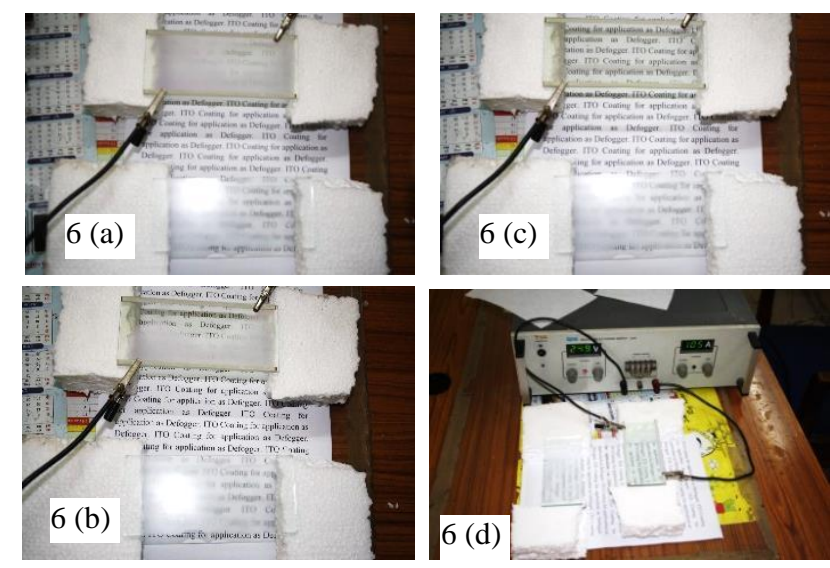

Fig. 6 (a, b, c, d). Defogging experimental setup

At this power, it takes almost 30 seconds for the complete removal of fog layer from the sample (figure 6 (c)) and the text underneath could be read without any difficulty. Figure 6 (b) shows a moment when the fog removal was in the process and half of the glass was clear and half was still foggy. Figure 6 (d) shows 
the complete experimental setup with the samples, external DC power supply, electrical connections and the voltage and current readings.

\section{Conclusions}

ITO coatings having high transmission and low sheet resistance are successfully deposited over glass substrates and their use as defogger is demonstrated. These ITO coatings can also be used for front contact electrode in the HIT solar cell as high transmission and low sheet resistance of ITO coatings is the requirement there as well. The deposited coatings are characterized using XRD and are found to be crystalline in nature with (222) preferred orientation for thin coating samples of $700 \mathrm{~A}^{\circ}$ and (400) preferred orientation for thick coating samples of 0.25 microns. SEM study revealed that the coating is dense granular and the grain size appears to vary in between 50 to $100 \mathrm{~nm}$. The deposited coatings exhibited low sheet resistance in between $40 \Omega / \square$ to $50 \Omega / \square$ and the average transmission of more than $80 \%$ in between $500 \mathrm{~nm}$ to $750 \mathrm{~nm}$ wavelengths. Experimentally it is proven that these ITO coated glass samples could be used efficient defrosting of fog layer as well as their optical and electrical properties make them suitable for use in HIT solar cell.

\section{Acknowledgments}

The author would like to acknowledge BHEL management for providing an opportunity to work on this project. Author would like to thank National Physical Laboratory (NPL) for XRD and SEM characterization and Mr. Vaibhav Nasery a research scholar at IIT Bombay for XRD and SEM analysis at IIT Bombay. Author would also like to acknowledge two intern students Mayank Arora and Jayant Sharma from Thapar University for their help during experimentation.

\section{References}

L. Kerkache, A. Layadi, F.Hadjersi, E. Dogheche, et. al., (2010), Sputtered Indium Tin Oxide thin films deposited on glass substrate for photovoltaic application, International Conference on Renewable Energies and Power Quality (ICREPQ'10) Granada (Spain), 23th to 25th March, 2010.

Minami, T., (2005), Transparent conducting oxide semiconductors for transparent electrodes, Journal of Semiconductor Science and Technology, 20, S35-S44.

Venkat, S., Dunsky, C., (2006), Laser Patterning of ITO in Flat Panel Display Manufacturing, Photon Processing in Microelectronics and Photonics V Photonics West, San Jose, Proceedings of SPIE Vol. 6106, pp. 610602.

T. K. Kim et. al., (2009), GaN-based light-emitting diode with textured indium tin oxide transparent layer coated with Al203 powder, Appl. Phys. Lett. 94, 161107.

Subrata Roy, Haribalan Kumar, Richard Anderson, (2005), Efficient defrosting of an inclined flat surface, International Journal of heat and mass transfer, 48, pp. 2613-2624.

A. Farag, L.J. Huang, (2003), CFD analysis and validation of automotive windshield de-icing simulation, $S A E$ International, 2003-01-1079.

R. W. Gent, N.P. Dart, J.T. Cansdale, (2000), Aircraft icing, Philosophical Transactions of the Royal Society A. 358, pp. 2873-2911.

SAE International, (2003), Surface Vehicle recommended practice, Passenger Car Windshield Defrosting systems, SAE International J902, Review, July 2003.

M. Nisha, M.K. Jayaraj (2008), Applied Surface Science 255, pp. 1790-1795.

L. Kerkache, A. Layadi, A. Mosser, (2009), journal of Alloys and Compounds 485, pp. 46-50.

T.F. Stoica, V.S. Teodorescu, M.G. Blanchin, M. Gortner, M. Losurdo, M. Zaharescu, (2003), Materials Science and Engineering B 101, pp. 222.

J. B. Choi, J. H. Kim, K.A. Jeon, S. Y. Lee, (2003), Materials science and Engineering B 102, pp. 376-379.

Chen Y, Zhou Y et. al., (2007), Journal of Materials Science Materials in Electronics 18, pp. 411.

Ocal Tuna, Yusuf Selamet et. al., (2010), Journal of Physics D: Applied Physics. 43, pp. 055402.

Shui-Yang Lien, (2010), Thin Solid Films 518, pp. 510-513. 